\title{
Monetary Value of a District's Flexibility on the Spot- and Reserve Electricity Markets
}

\author{
Emanuele Facchinetti ${ }^{1}$, Beni Rohrbach ${ }^{1, *}$, Gerko van der Wel ${ }^{2}$ and Andrew Bollinger ${ }^{3}$ \\ 1 Lucerne University of Applied Science and Arts, 6048 Horw, Switzerland; facchinetti.emanuele@gmail.com \\ 2 Misurio AG, 3930 Visp, Switzerland; gerko.vanderwel@misurio.ch \\ 3 Urban Energy Systems Laboratory, Swiss Federal Laboratories for Materials Science and Technologies, \\ EMPA, 8600 Dübendorf, Switzerland; andrew.bollinger@empa.ch \\ * Correspondence: benjamin.rohrbach@hslu.ch; Tel.: +41-(0)-41-349-35-02
}

Received: 16 August 2018; Accepted: 6 December 2018; Published: 18 December 2018

check for updates

\begin{abstract}
In the future, advanced multi-energy systems are expected to handle an increasing share of fluctuating renewable energy generation through the management of multiple advanced energy conversion and storage technologies operating across different energy carriers. The market diffusion of such concepts of Local Energy Management-the management of energy supply, demand, and storage within a given geographical area-is expected to provoke a fundamental reorganization of the power generation sector. This work contributes to this topic by estimating the maximum potential economic value attained from using the flexibility of a district to take advantage of operating within multiple electricity markets at the same time. The study is based on the measured demand and production data of a newly built suburban residential district located in Central Switzerland. The actual configuration of the district and the resulting flexibility, as well as an extension with a battery storage system, is used to estimate the economic value of the flexibility. Then, an optimization algorithm manages flexible demand, production, and storage capacities in order to alternatively maximize the revenues/cost savings, self-sufficiency, or share of renewable resources of the district's energy supply. In this vein, the impact of the way the system operates in the markets regarding the degradation of the battery is assessed and its pay-back-time is estimated. The analysis revealed a considerable profit potential associated with the district thermal and electricity storage flexibility, in particular, when operating on both the spot and reserve electricity markets. Firstly, it was shown that overall energy costs can be minimized through an optimal management of energy conversion and storage systems. Secondly, complementing the infrastructure with batteries and trading flexibility on the spot market would decrease costs by about $43 \%$, while an additional $20 \%$ cost decrease could be captured by including trading on the reserve market. Thirdly, it has been shown that operation on the spot- and reserve market does not seem to degrade the battery more than solely operation on the spot market. However, when operating on the spot- and reserve markets, battery amortization would still take about 10 years.
\end{abstract}

Keywords: distributed generation; energy hubs; energy markets; Local Energy Management; multi-energy systems

\section{Introduction}

In the future, the European energy system is expected to exhibit an increasing share of fluctuating renewable energy sources [1]. This requires the management of multiple advanced energy conversion and storage technologies operating across different energy carriers to optimize the rational conversion of bio and fossil resources through dedicated multi-energy-systems. This is best understood with the concept of an energy hub, firstly introduced by Geidl et al. [2] and further expanded by 
multiple researchers [3-5]. On an urban scale, possible environomic (i.e., thermodynamic, economic, and environmental) advantages of energy hubs with respect to conventional centralized energy systems were described by several researchers. For example, Chicco and Mancarella [6] as well as Koirala et al. [7] highlight the possibility to deliver more environmentally friendly energy services at lower costs, both for the system, due to the potential for grid stabilization, as well as for the individual customer, due to the possibility of benefiting from varying market prices. However, due to the increased complexity of such systems, one needs to incorporate a more holistic perspective when assessing the economic benefits [8,9]. As a consequence, there is a lack of studies assessing multiple economic value streams of a distributed energy system simultaneously.

The local management of the energy supply, demand, and storage is expected to provoke a fundamental reorganization of the power sector, yielding new emerging business opportunities [10]. Amongst others, the market valorization of the flexibility offered by the combination of smart grids and distributed generation is considered as a promising new business opportunity. Already in 2013, Mancarella and Chicco [11] described the benefits emerging from the ability of multi-energy-systems to shift loads from one energy carrier to another and store energy in various forms and exploit such flexibility on ancillary services markets. As a consequence, for example, research was performed to estimate the value of the flexibility of multiple aggregated prosumers for the spot market under given bidding rules [12]. Other studies have dealt with the development of control schemes to optimize local energy management considering possibilities for market participation [13,14], stochastic market prices [15], and locally distributed intelligence for grid congestion and management [16]. All of these studies indicate a large potential of the local flexibility. Still lacking, however, is an assessment of the monetary value of local energy systems flexibility considering simultaneous participation in both the spot and reserve electricity markets.

Some researchers have identified the cost of locally produced flexibility to be much larger than the one in spot- and reserve markets [17]. However, they (a) didn't study the possible revenue out of the flexibility which is already present but only emerges by understanding the energy system as an energy hub and (b) didn't explicitly list the specifications of the technologies in detail, such as for example the assumed number of cycles for the battery. Other studies highlight regulatory and market limitations for making economic benefits from distributed flexibility aggregators but generally agree on the importance of incorporating distributed flexibility into future energy systems [18]. Besides this, Ottesen et al. [19] have already described and investigated the best decision rules and the impact of incomplete knowledge on the total profitability for a flexibility aggregator when operating simultaneously on reserve markets and spot markets. However, they were only considering the tertiary, and not, additionally, the secondary, reserve markets and were estimating the profitability for only eight weeks, while this study covers a whole year.

This work is the first to assess the maximal potential valorization of the flexibility associated with Local Energy Management solutions at the district level in various electricity markets both simultaneously and separately over a whole year. It may serve as a stepping stone for further researchers to investigate the maximum profitability in other cases and show ways to exploit this potential. As shown, the existing literature focuses on the valorization of the local flexibility only with respect to selected markets. The novel contribution provided by the present study relates to the original approach of considering the options of valorizing the available local energy management flexibilities on both the spot and two-reserve electricity markets simultaneously. The research presented in this paper builds on the presented previous studies which have already highlighted, described, and partly characterized the potential profitability of local-scale multi-energy systems for the provision of ancillary services. However, no study to date has investigated the optimal local energy management in multi-energy systems by considering the possibility of simultaneous participation in multiple markets.

The innovative approach applied in this study builds upon the development of an optimization algorithm that provides the optimal management of the available flexible demand, production, and storage capacities in order to maximize the revenues and the cost savings obtainable from trading 
at the same time on both the spot and multiple-reserve electricity markets. The study shows the potential based on the measured demand and production data of a newly built suburban residential district located in Central Switzerland and assesses the revenue potential ex-post. The district consists of six multi-family residential buildings and relies on the interaction of electricity and thermal networks, including renewable production through photovoltaic and solar thermal panels, as well as several thermal storage options.

In addition, the option of including batteries has been considered. We pose the hypothesis that providing flexibility to various markets is expected to affect battery cycling, which is limited by the products' characteristics. For stationary lithium-ion batteries, a lifetime of 10 years and an average number of 10,000 cycles is guaranteed, with the batteries health largely depending on its operation in optimal conditions $[20,21]$. Among the factors most affecting the degradation of a battery are the current, the depth of discharge, the state of charge, and the temperature [22]. As the optimizer does not affect temperature, this is considered to be outside of the system boundaries. In commercially available solutions the battery management systems ensure that the battery is not run outside its technical specification. However, even when operated within a technically safe operating range, the optimal State of Charge (SoC) limits, with respect to minimal battery degradation, have been reported as between $20 \%$ and $85 \%$ SoC [23]. Electricity cycled either below or above the recommended SoC-levels accelerates battery degradation. As the optimizer impacts the amount of electricity stored at low and high states of charge, we assess the amount of energy cycled in total and, particularly, outside these recommended boundaries. As a consequence, our simple battery degradation model is similar to the one applied in [17], which is based on the number of full cycles; however, we expanded it by explicitly considering at which SoC the charging and discharging occurs.

The paper is organized as follows. In Section 2, the use-case district and the applied optimization algorithm are described. In Section 3, the results of the analysis are presented and discussed. Finally, conclusions are drawn in Section 4.

\section{Methodology}

\subsection{The Case Study: Suurstoffi}

The case study used in this project refers to a district named Suurstoffi in Rotkreuz in Central Switzerland. The district has been under construction since 2011. When completed, the district will account for about 30 buildings dedicated to residential and commercial use. The present investigation refers to six residential multi-family buildings including 141 flats operating since 2012 and accounting annually for electricity demand of about $0.7 \mathrm{GWh}, 1 \mathrm{GWh}$ of combined sanitary water (SW) and space heating (SH), and $50 \mathrm{MWh}$ of cooling demand [24]. The reference SH consumption is $36.5 \mathrm{kWh} / \mathrm{y} / \mathrm{m}^{2}$. In Figure 1a, the Suurstoffi district is shown, and the considered buildings are outlined in orange. The electricity, heating, and sanitary water demands of these buildings, as well as the available solar radiation, have been monitored at a 15-min resolution since 2012 [25]. Previous studies focusing on the Suurstoffi district used optimization techniques to evaluate the performance of the site's energy system [26] and evaluated possibilities for façade photovoltaics [26]. Neither considers the possibilities for the participation of the electricity market. This study considers the load profiles and energy market prices referring to the full year 2013. The considered mix of the Swiss electricity grid consists out of about $55 \%$ of renewable energy [27].

As shown in Figure 1b, the buildings are equipped with heat pumps for $\mathrm{SH}$ and $\mathrm{SW}$ production which are connected to SH and SW thermal storages. A low-temperature thermal network connects the buildings in the district and serves as a heat source for the building-level heat pumps (HP). Photovoltaic (PV) and hybrid solar thermal and photovoltaic panels (PVT) are located on the roof of each building. The heat provided by the solar panels feeds the SW and SH thermal networks. Furthermore, a ground borehole field, connected to the low-temperature network, is used as seasonal storage serving as a 
heat source for the SH and SW and as a heat sink for all excess heat (i.e., from cooling and excess heat production). For further details on the building energy infrastructure, refer to [25].

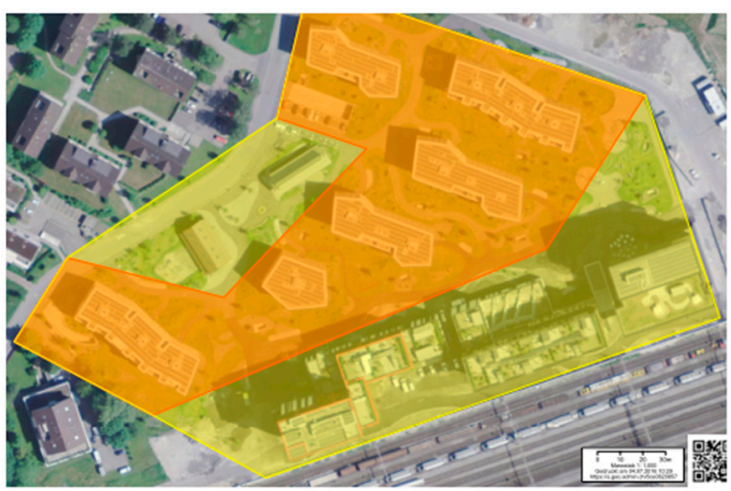

(a)

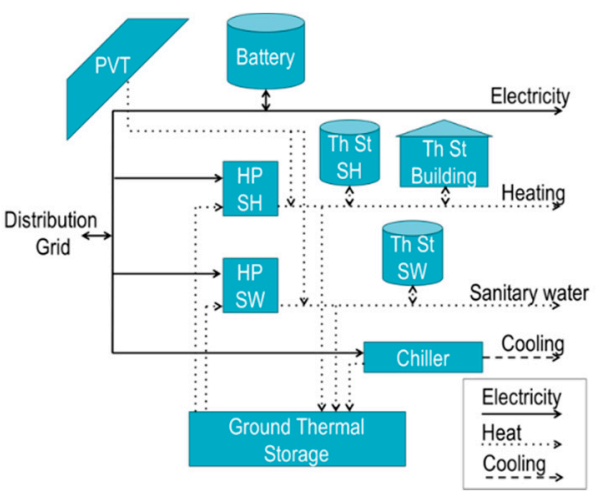

(b)

Figure 1. (a) Aerial view of the west side of the Suurstoffi district (yellow). The considered buildings are outlined in orange [24]; (b) Multi-energy infrastructure on the single-building level.

With respect to the existing energy infrastructure, the current study considers the cooling to be provided by a chiller (instead of the existing free cooling), to cover for the fairly small $50 \mathrm{MWh}$ cooling demand. Furthermore, the thermal network connecting the buildings has not been explicitly modeled. Additionally, a specific scenario considering the integration of batteries has been evaluated. The main features of the modeled energy infrastructure are summarized in Table 1 for each building.

Table 1. Energy infrastructure features.

\begin{tabular}{|c|c|c|c|c|c|c|}
\hline Building $\mathrm{n}^{\circ}$ & 1 & 2 & 3 & 4 & 5 & 6 \\
\hline Floor surface $\left[\mathrm{m}^{2}\right]$ & 4111 & 1747 & 2852 & 3212 & 4227 & 2822 \\
\hline SH storage capacity [kWh] & 46 & 35 & 46 & 46 & 46 & 46 \\
\hline SW storage capacity [kWh] & 114 & 57 & 71 & 86 & 114 & 86 \\
\hline $\begin{array}{l}\text { Thermal mass building } \\
\text { capacity }[\mathrm{kWh}]\end{array}$ & 41 & 17.5 & 28.5 & 32.1 & 42.3 & 28.2 \\
\hline $\begin{array}{l}\text { Ground storage thermal } \\
\text { capacity }[\mathrm{kWh}]\end{array}$ & 200 & 92 & 150 & 172 & 220 & 148 \\
\hline $\begin{array}{l}\text { Battery capacity [kWh] } \\
\text { Baseline/Battery scenario }\end{array}$ & $0 / 40$ & $0 / 40$ & $0 / 40$ & $0 / 40$ & $0 / 40$ & $0 / 40$ \\
\hline Solar PVT surface $\left[\mathrm{m}^{2}\right]$ & 215 & 112 & 168 & 206 & 211 & 154 \\
\hline PVT Thermal Efficiency [-] & \multirow{2}{*}{\multicolumn{6}{|c|}{$\begin{array}{c}0.7 \\
0.18\end{array}$}} \\
\hline PVT Electric Efficiency [-] & & & & & & \\
\hline Solar PV surface $\left[\mathrm{m}^{2}\right]$ & 212 & 112 & 168 & 206 & 211 & 154 \\
\hline PV Electric Efficiency [-] & \multicolumn{6}{|c|}{0.18} \\
\hline HP SH max power $[\mathrm{kW}]$ & 127 & 127 & 127 & 127 & 127 & 127 \\
\hline HP SH COP [-] & \multicolumn{6}{|c|}{5.5} \\
\hline HP SW max power [kW] & 340 & 340 & 340 & 340 & 340 & 340 \\
\hline HP SW COP [-] & \multicolumn{6}{|c|}{4} \\
\hline HP cooling max power $[\mathrm{kW}]$ & 300 & 300 & 300 & 300 & 300 & 300 \\
\hline HP cooling COP [-] & \multicolumn{6}{|c|}{4.5} \\
\hline
\end{tabular}

\subsection{The Optimization towards the Spot and Power Reserve Electricity Markets}

The applied optimization algorithm is part of the commercial solution of the company MISURIO AG [28]. It manages flexible demand, production, and storage capacities in order to maximize the revenues obtainable from the spot electricity market and the electricity reserve market. The optimizer is designed for multi-energy systems where different types of energy production, demand, and storages are combined. The elements in these systems can be divided into two categories. Firstly, energy 
conversion devices (e.g., heat pumps, PV systems, oil boilers, and potential power-to-gas units), and secondly, energy storages (e.g., electricity, gas, and thermal storages). The latter also includes the thermal mass from the buildings, which is utilized as the thermal energy storage.

Since the optimization not only considers the spot market but also the electricity reserve market, the model needs to consider reserve energy flows, as well as the actual energy flows. If for example, a heat pump is used to offer positive balancing power, it needs to be run at this given power level during the time period that the balancing power is offered. When a call for this power is made, the heat pump would then reduce its power. Meanwhile, the amount of heat in the storage needs to be high enough to ensure that the heat demand is always met. This obviously also affects the previous load profiles of the heat pump and interacts with locally produced heat and electricity. As a consequence, a system of complex interdependencies results, with an optimal operation for a given optimization objective.

The optimum of this complex system of linear equations is then solved with the use of a commercial solver (IBM ILOG CPLEX Optimizer) [28]. To this end, the flows between all the system elements and those coming from the outside, in addition to the state of the storages are transformed to a large system of linear equations that affect each other at every given timestep. In this study, the solver objective function is the minimization of all costs and the maximization of all yields. The cost components considered are the result of energy exchanges with the grid, the costs associated with the maximum power taken from the grid in a month, and the cost of fuel, if applicable. The revenues are obtained from trading locally produced energy and flexibility on the spot- and reserve electricity markets.

As a consequence, the optimizer requires a given scenario of the future and does not require a decision matrix concerning how to bid and operate on various markets as it will automatically choose the economically most profitable bidding strategy. This approach was deemed to be suitable, as the aim is to assess the potential value of flexibility in a market and not to assess the impact of a certain decision heuristic as in [12] or the impact of incomplete knowledge on the total revenues as in [19].

With the right choice of parameters, the optimizer can also prioritize the self-sufficiency (1) and the share of renewable energy sources (2) of the district in the optimization. Additionally, when no weight is given to self-sufficiency or renewable sources, and the prices are fixed in time, the optimization will find the best solution in terms of the least energy conversion and storage losses. Both self-sufficiency and 'share of renewables' are calculated on a monthly- and yearly basis. The yearly share of renewables and self-sufficiency is calculated as an average of the monthly shares.

$$
\begin{gathered}
\text { Self-sufficiency }=k W h_{\text {el produced }} /\left(k W h_{\text {el imported }}+k W h_{\text {el produced }}-k W h_{\text {el exported }}\right) \\
\text { Share of renewables }=1-\left(k W h_{\text {el not renewable }} / k W h_{\text {el tot }}\right)
\end{gathered}
$$

The energy flow between the different devices is calculated at a 15-min resolution, taking into account the energy conversion efficiency and maximum power for each device. For the energy storage elements, the minimum and maximum storage capacity and storage losses are also considered. The various elements are connected to each other through the thermal, electrical, and gas grids. Demand, production, and market prices are specified as time series at a 15-min resolution. In the present case study, no gas grids and power-to-gas conversion utilities are considered as they are not present in the studied district.

The optimizations cover the entirety of the year 2013, and consider, as inputs, the measured energy demand and solar radiation profiles in 2013. For the profitability estimation, the prices from the Swiss electricity spot market and the Swiss electricity reserve market, including secondary (four-hours blocks) and tertiary (one-week blocks) have been considered [19]. In this analysis, grid connection costs and taxes applicable to the energy imported from the grid, and potential feed-in tariff have not been considered. 


\section{Results and Discussion}

This section presents the results of the optimization. In Section 3.1, the baseline scenario is presented, which reflects the existing infrastructure in the district (with the exception of free cooling, as mentioned in Section 2). Secondly, in Section 3.2, sensitivity analyses aiming to assess the role of the different available thermal storage options are presented. Thirdly, in Section 3.3, the scenario including batteries is considered. Fourthly, in Section 3.4, the impact of trading the flexibility on both the spot and reserve markets is presented for both scenarios. Finally, the impact on the battery is discussed in both scenarios.

\subsection{Baseline Scenario}

The monthly total primary energy exchanges related to the baseline scenario are summarized in Figure 2a. The overall primary energy demand is about $50 \%$ lower during summertime than in wintertime. Local renewable energy (electricity and thermal energy from PV and PVT) is mostly produced in summertime. As a consequence, electricity is imported from the grid in wintertime and exported in summertime.

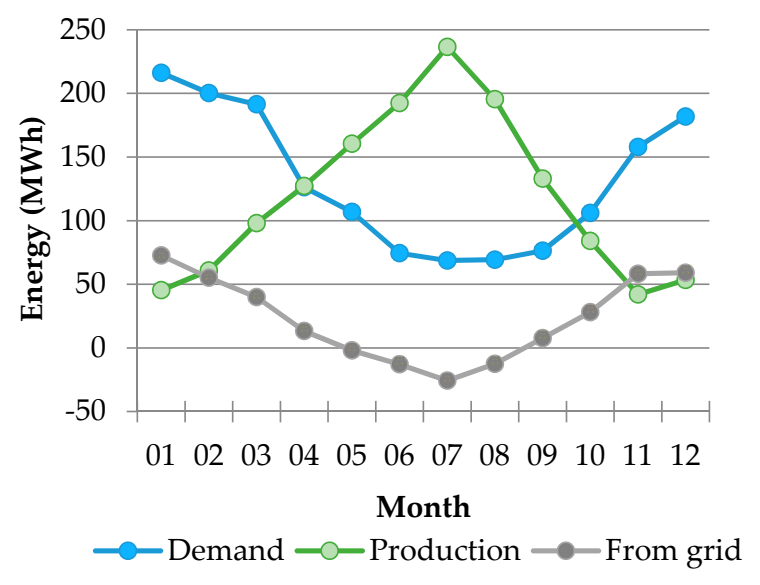

(a)

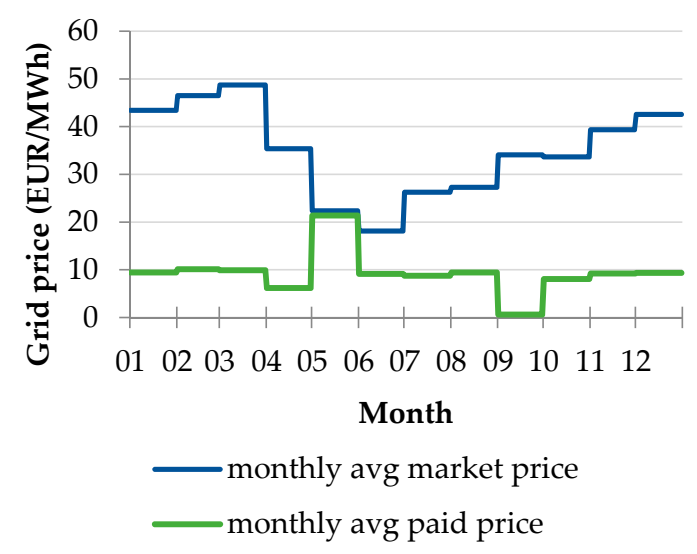

(c)

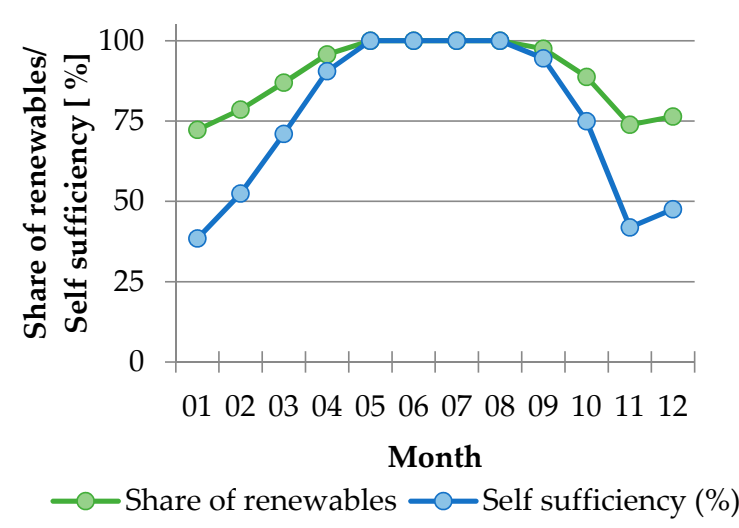

(b)

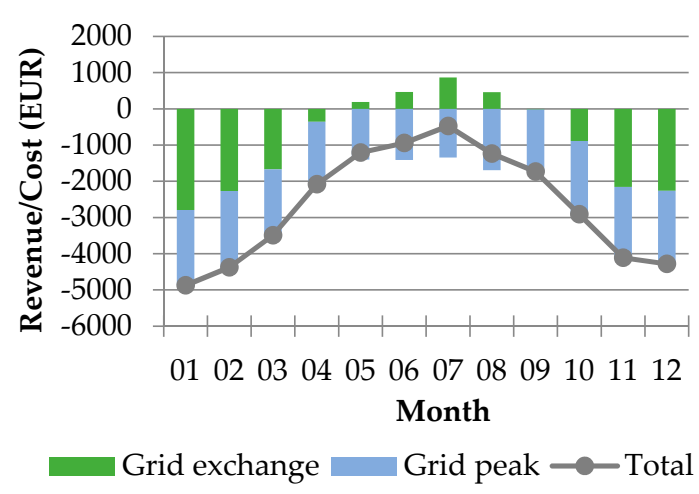

(d)

Figure 2. Baseline scenario: (a) Monthly primary energy exchanges; (b) monthly share of renewables and rate of self-sufficiency; (c) grid price; (d) monthly revenue/cost results.

In Figure $2 b$, the split between local vs. imported and renewable vs. non-renewable resources is presented. The self-sufficiency and the share of renewables reach, in a monthly average, $100 \%$ in summertime, when the PVT production is at its maximum level and there is no SH demand. 
In wintertime, the share of renewables decreases to a minimum of $75 \%$, while self-sufficiency goes down to $40 \%$. This difference between the two indices is due to the fraction of renewable energy imported from the grid in wintertime (i.e., $55 \%$ of the grid electricity mix). Considering the average over the year of the monthly averages, the system achieves a share of $92 \%$ renewables and a self-sufficiency of $83 \%$. Figure $2 \mathrm{c}$ compares the average monthly market price and the average market price paid by the district. The applied optimization approach enables the minimization of the costs; in every month of the year, the average paid electricity price is lower than the average market price. Figure $2 \mathrm{~d}$ presents the monthly distribution of revenues and costs related to the grid exchange, including, the revenue/costs streams associated with trading on the spot market (i.e., grid exchange), and the cost associated to the monthly maximum power taken from the grid (i.e., grid peak). Grid peak costs vary by about $35 \%$ between the maximum cost in January and the minimum cost in July. The electricity trading activity with the grid provides a positive cash flow from May to September. However, even in the summer months, it does not compensate for the grid peak costs and overall in every month, the costs are higher than the benefits. The annual cumulative cost/revenues balance amounts to a cost of about $31,000 €$.

\subsection{The Influence of Thermal Energy Storages}

Sensitivity analyses have been run to investigate the different contribution of each available thermal storage option, namely, the sanitary water storage, the space heating storage (including the building thermal capacity), and the ground storage. Individual optimizations have been run, excluding one thermal storage option at a time. The resulting yearly profit, share of renewables, and self-sufficiency analyses results are shown in Table 2.

Table 2. Sensitivity of yearly profitability, self-sufficiency, and share of renewables depending on thermal storages.

\begin{tabular}{|c|c|c|c|c|}
\hline Scenario & Costs/Revenue & e Yearly Balance & Self-Sufficiency & Share of Renewables \\
\hline Unit & [EUR] & {$[\%]$} & {$[\%]$} & {$[\%]$} \\
\hline All thermal storages & $-31,733$ & 0 & 83.6 & 92.6 \\
\hline Excluding SW storage & $-31,902$ & -0.5 & 83.3 & 92.5 \\
\hline $\begin{array}{l}\text { Excluding } \mathrm{SH} \text { and building } \\
\text { thermal capacity storage }\end{array}$ & $-32,626$ & -2.8 & 82.8 & 92.3 \\
\hline Excluding ground storage & $-32,028$ & -0.2 & 83.6 & 92.6 \\
\hline $\begin{array}{l}\text { Excluding all thermal } \\
\text { storage options }\end{array}$ & $-40,845$ & -28.7 & 81.9 & 91.9 \\
\hline
\end{tabular}

The analyses show that excluding a single thermal storage option does not significantly impact the overall results. This indicates that the other thermal storages compensate the removal of a single thermal storage. When the SH storage is excluded, the use of the ground storage option is significantly higher (about $40 \%$ more). Despite the fact that the ground storage is a relatively less efficient storage option with respect to the SH storage, the impact on the overall profit, self-sufficiency, and share of renewables is marginal. A significant impact on the results is detected only when excluding all thermal storage options. In this latter scenario, the overall annual cost increases by about $29 \%$, and the annual self-sufficiency decreases of about $2 \%$.

In general, the performed sensitivity analyses enable to conclude that the flexibility associated with the thermal storage options in residential newly built districts-such as the case study here investigated-, if valorized in the electricity spot market, can generate additional revenues reducing the yearly total expenses of about $30 \%$.

\subsection{Scenario with Batteries}

The influence of including batteries as an electricity storage option has also been investigated. With respect to the baseline scenario, $40 \mathrm{kWh}$ of battery capacity has been included in each building 
model for a total district battery capacity of $240 \mathrm{kWh}$. The optimization results referring to this scenario are presented in Figures 4 and 5.

Energy production and demand profiles have been kept unchanged with respect to the baseline scenario. A small, yet noticeable and interesting difference between the baseline and the battery scenarios appears with regard to the amount of electricity exchanged with the grid; about $7 \%$ more electricity is exchanged with the grid over the time horizon of the model. This is coherent with the fact that the optimizer favors the electricity exchanges with the grid and uses the batteries to take advantage of the electricity price variation in the spot market. This leads to the surprising result, shown in Figure 3 and Table 3, where the annual share of renewables and the self-sufficiency levels are slightly lower in the battery scenario than in the baseline scenario. This is explicable considering that, due to the selected optimization objective- the maximization of the profitability-the optimizer operates the battery to maximize the profit from the electricity trading. The side effects of such an operating strategy are higher energy losses in the batteries and, therefore, a higher positive net import of electricity from the grid.

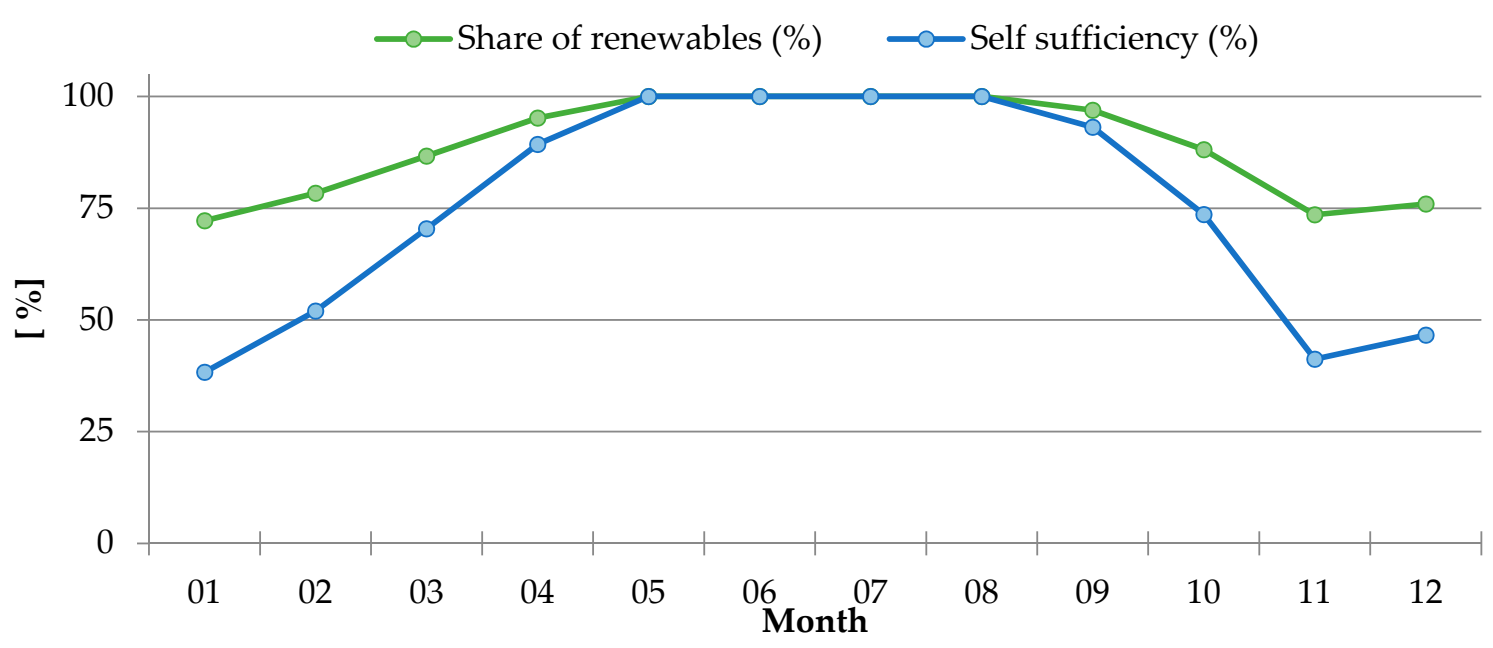

Figure 3. Battery scenario: Monthly share of renewables and self-sufficiency.

Table 3. Yearly profitability, self-sufficiency, and share of renewables for the baseline vs battery scenarios.

\begin{tabular}{ccccc}
\hline Scenario & \multicolumn{2}{c}{ Costs/Revenue Yearly Balance } & Self-Sufficiency & Share of Renewables \\
\hline Unit & {$[$ EUR] } & {$[\%]$} & {$[\%]$} & {$[\%]$} \\
\hline Baseline & -31733 & 0 & 83.6 & 92.6 \\
Battery & -17925 & +43.5 & 82.5 & 92.1 \\
\hline
\end{tabular}

Figure 4 presents the monthly revenues/costs balance for the battery scenario. With respect to the baseline scenario, shown in Figure $2 \mathrm{~d}$, the profit advantage related to the batteries is significant. The monthly cost/revenues balance is positive from May to August. Overall, during the course of a year, the batteries enable a cost reduction of approximately $43 \%$. However, the cumulative annual operative income stays negative. Considering the current market cost of batteries for residential applications, which in Switzerland is about $1000 €$ per installed $\mathrm{kWh}$, the cost difference between the baseline and battery scenarios would amortize the batteries' cost in about 15 years [20,21]. 


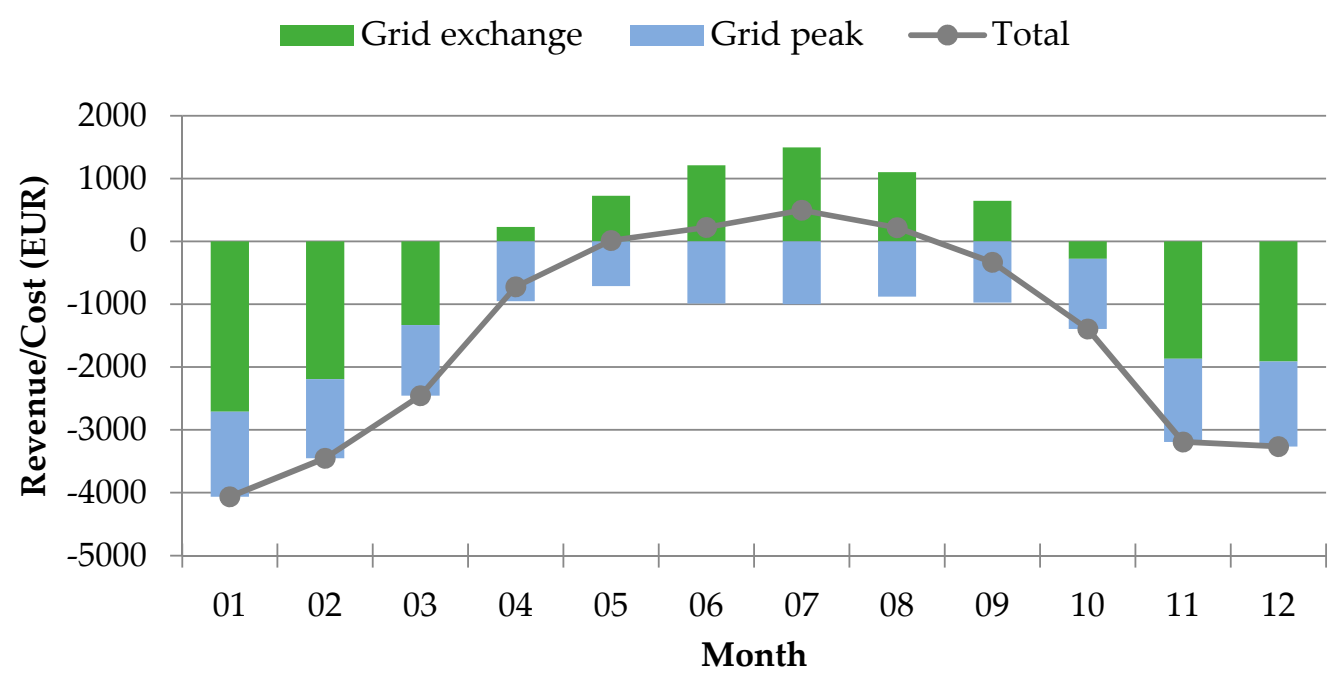

Figure 4. Battery scenario: Monthly revenue/cost results.

\subsection{The Contribution of the Reserve Market}

In this section, the impact of trading the available flexibility on both the spot- and reserve electricity markets is analyzed. The optimizer has the option to trade the flexibility either in the reserve or in the spot market or to define an optimal repartition between the two options. The overall results of all the different scenarios analyzed are summarized in Table 4.

Table 4. Yearly profitability, self-sufficiency, and share of renewables for the baseline vs battery scenarios considering both spot and reserve markets.

\begin{tabular}{|c|c|c|c|c|}
\hline \multirow{2}{*}{$\begin{array}{c}\text { Scenario } \\
\text { Unit }\end{array}$} & \multicolumn{2}{|c|}{ Costs/Revenue Yearly Balance } & \multirow{2}{*}{$\begin{array}{c}\text { Self-Sufficiency } \\
{[\%]}\end{array}$} & \multirow{2}{*}{$\begin{array}{c}\text { Share of Renewables } \\
{[\%]}\end{array}$} \\
\hline & [EUR] & {$[\%]^{1}$} & & \\
\hline Baseline & -26373 & +16.91 & 83.5 & 92.5 \\
\hline $\begin{array}{l}\text { Baseline w/o } \\
\text { thermal storage }\end{array}$ & -40845 & -28.7 & 81.9 & 91.9 \\
\hline Battery & -11375 & +64.2 & 82.5 & 92.1 \\
\hline $\begin{array}{c}\text { Battery w/o } \\
\text { thermal storage }\end{array}$ & -21672 & +31.7 & 80.7 & 91.3 \\
\hline
\end{tabular}

${ }^{1}$ Costs/revenues balance: baseline scenario, spot market only $=0 \%$, c.f. Table 3 .

Figure 5a shows the yearly distribution of costs and revenues obtained from the optimization of the baseline scenario. The total yearly costs/revenues balance remains negative with a total cost of about $26,000 €$. The ancillary services provided to the reserve market reduce the costs by $16 \%$ with respect to the spot-market-only equivalent scenario. The reserve market revenues are uniformly distributed throughout the year, except for a very high positive peak in April 2013 in which market prices have been particularly favorable in the reserve market.

In Figure 5b, the yearly revenues/costs balance is presented for the battery scenario. Integrating the batteries into the existing infrastructure and trading the flexibility on both the spot and reserve markets would reduce costs by about $47 \%$ with respect to the corresponding baseline scenario. In this more favorable scenario, the payback time of the batteries decreases to about 10 years, which is the guaranteed lifetime of current, commercially available products [29]. This is in contrast to another study [17], which indicated that a battery is economically not viable for providing flexibility to different markets. The different results can be explained by this other study considering only a single market and not considering the integration of the battery within an energy hub. 


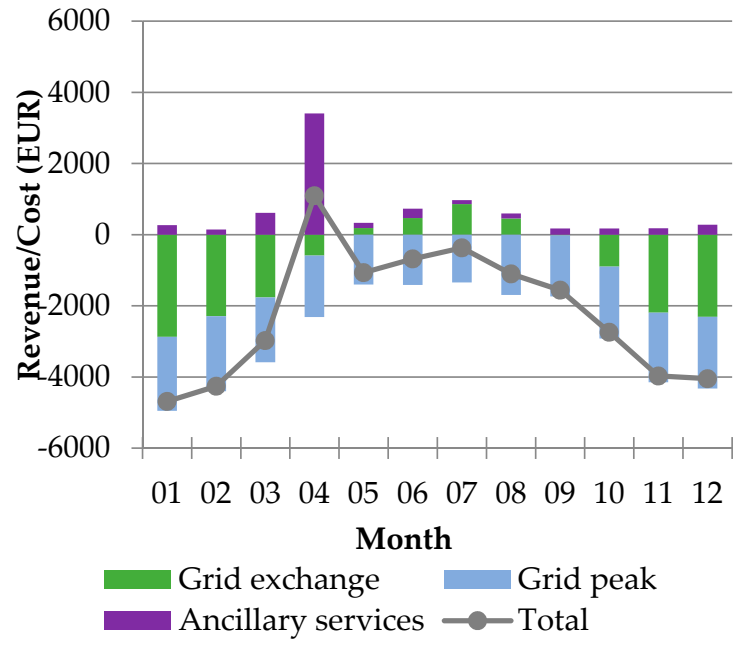

(a)

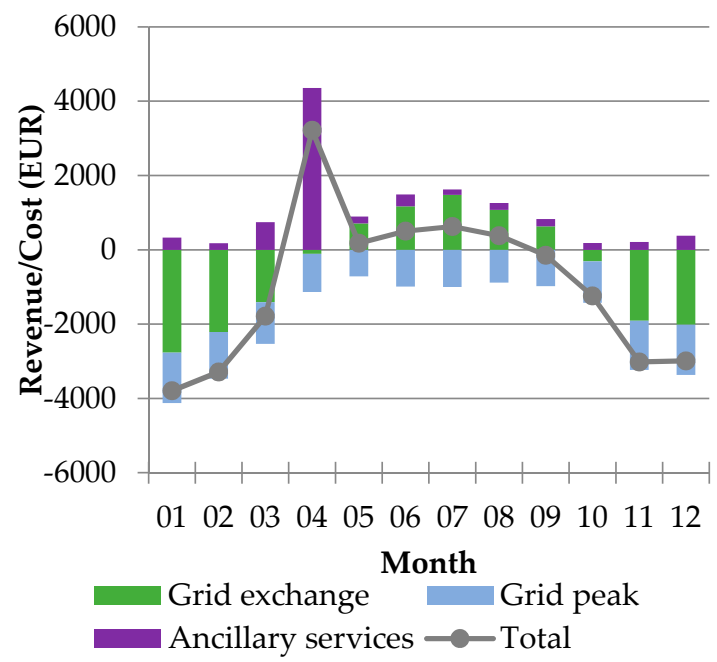

(b)

Figure 5. Monthly revenue/cost results: (a) Baseline including reserve market; (b) battery scenario including reserve market.

Finally, in order to investigate the interaction between electricity and thermal storage, an optimization including the batteries and excluding all thermal storage options has been performed. The overall results of this optimization are presented in Table 4 . The analysis shows that, with respect to an ideal scenario excluding both storage options (baseline scenario w/o thermal storage), the electricity storage achieved costs savings of approximately $47 \%$ (battery scenario w/o thermal storage), while the thermal storage reduced costs by approximately $35 \%$ (baseline scenario). However, the thermal storage enables a higher self-sufficiency and share of renewables levels to be achieved. It is interesting to note that the combination of electricity and thermal storage options (battery scenario) lowered costs less $(72 \%)$ than the hypothetical case where the battery-only and thermal storage-only optimal costs/revenues balances are summed $(82 \%)$.

\subsection{Battery Operation}

Battery cycling for discharging at a different $\mathrm{SoC}$ for both scenarios is depicted in Figure 6. Each bar in Figure 6 represents the amount of electricity discharged within a specific range of the SoC. For example, the leftmost two bars represent the amount of electricity discharged when the battery SoC was between $100 \%$ and $90 \%$. It is sufficient to just look at the discharged volume, as the charging and discharging volume are approximately balanced over the course of a year. The SoC at the end of the year was different only by about $60 \mathrm{kWh}$. In other words, each discharged MWh of electricity at a given $\mathrm{SoC}$ first needs to be charged at this SoC. To then roughly assess the degradation, it is sufficient to sum the discharged (or charged) $\mathrm{kWh}$ outside of the SoC limits recommended in the literature [23].

Table 5 presents the battery energy flows for operation of the district on the spot market only and the spot- and reserve markets.

As can be seen from Table 5, the battery undergoes a similar amount of full cycles operating on the spot- or on the spot- and regulating market. Operating on the spot- and reserve market, the average number of battery load cycles per day is 2.5 , which is $5 \%$ lower than in the corresponding scenario that considers only the spot market. Similarly, the overall charged/discharged electricity below or above the recommended SoC level of $85 \%$, that would result in accelerated battery degradation, is about 160 MWh for both operation modes (with each 80 MWh charged and discharged, as shown in Figure 6). Operating on the spot market only, 39\% of the total 80 MWh cycled outside of from the literature-recommended SoC-limits are charged and discharged below a SoC of $20 \%$. Operating on the spot- and reserve market, increase this value to $51 \%$, indicating that the battery stays more often empty 
in order to be able to profit from negative tertiary regulating services. As a consequence, participating in both the reserve and spot markets does not seem to inflict increased battery degradation when compared to operation in the spot market only.

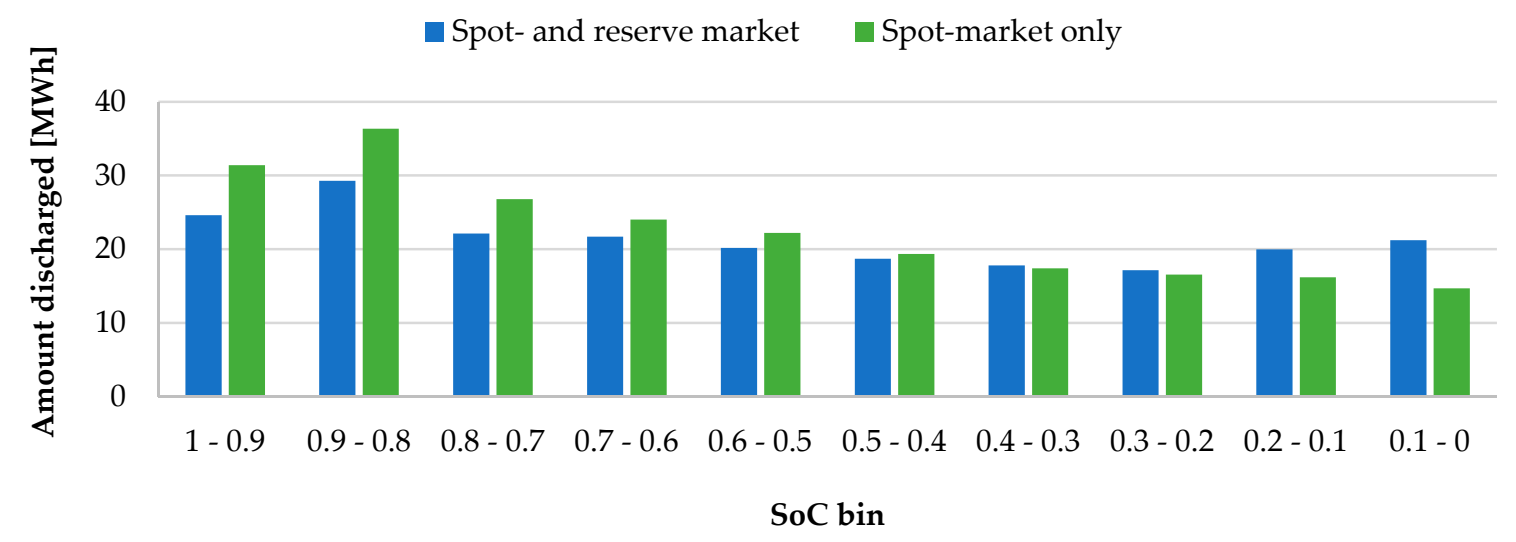

Figure 6. Battery cycling for two scenarios in specific (State of Charge) SoC-bins.

Table 5. Electricity charged below or above the recommended SoC-limits.

\begin{tabular}{ccccccccc}
\hline Scenario & $\begin{array}{c}\text { Total } \\
\text { Energy } \\
\text { Cycled }\end{array}$ & $\begin{array}{c}\text { Number } \\
\text { of Full } \\
\text { Cycles }\end{array}$ & \multicolumn{2}{c}{$\begin{array}{c}\text { Operation Below } \\
\text { 20\% SoC }\end{array}$} & \multicolumn{2}{c}{$\begin{array}{c}\text { Operation Above } \\
\text { 85\% SoC }\end{array}$} & $\begin{array}{c}\text { Total Energy Cycled } \\
\text { Below or Above } \\
\text { Recommended SoC }\end{array}$ \\
\hline Unit & {$[\mathbf{M W h}]$} & $\#$ & {$[\mathbf{M W h}]$} & {$[\%]^{\mathbf{1}}$} & {$[\mathbf{M W h}]$} & {$[\%]^{\mathbf{1}}$} & {$[\mathrm{MWh}]$} & {$[\%]^{\mathbf{2}}$} \\
\hline Spot market only & 450 & 937 & 62 & 39 & 98 & 61 & 160 & 36 \\
\hline $\begin{array}{c}\text { Spot- and reserve } \\
\text { markets }\end{array}$ & 426 & 886 & 82 & 51 & 78 & 49 & 160 & 38 \\
\hline
\end{tabular}

${ }^{1}$ Refers to the total energy cycled below of above the recommended SoC. ${ }^{2}$ Refers to the total energy cycled.

\subsection{Limitations}

The presented numbers reflect an ex-post analysis of the maximum revenue potential. Further studies would need to apply a rolling horizon approach in order to better account for uncertainties. However, this would require a second tool, that is able to predict demand, supply, and market prices for the area of study. As indicated by Ottesen et al. [19], imperfect information about the future could lower the revenues by as much as $30 \%$. In their study, the algorithm had difficulties regarding the prediction of future peak prices and was choosing strategies which are more flexible to avoid risks, which lowered the profitability. As a consequence, the total revenue depends on the quality of the predictions and the bidding strategy of the algorithm. However, in this study, we assessed the maximum revenue potential, which might help to guide further work on this topic and indicate the worthiness to invest time and resources in further tools.

Currently, the costs of battery degradation are not accounted for in the optimization. In future versions of the optimizer, the degradation of the battery could be incorporated to better account for the trade-offs under different optimization objectives and conditions. Additionally, the usable capacity of the battery is assumed to stay the same over the whole period of investigation. As we took manufacturer-guaranteed values, we deem this approach to be viable; however, future work could include more sophisticated battery degradation models. However, further research is needed to better estimate the likely impact of the operation and configuration of an energy hub on the battery. Nevertheless, we have shown, that the degradation is not greatly influenced by operating the energy hub either purely in the spot market or in the spot- and reserve markets. Hence, we consider the conclusions drawn to be robust in this respect. 


\section{Conclusions}

The present work provides insights into the potential valorization of the flexibility associated with Local Energy Management solutions at the district level in the electricity markets. Based on measured demand and production data, estimations were made on the achievable profit by trading the flexibility associated with a newly built suburban residential district on the spot- and reserve electricity markets. The district energy infrastructure relies on an energy hub integrating electrical and thermal networks and including renewable production through photovoltaic and solar thermal panels, as well as several thermal storage options. Furthermore, the option of including an electricity storage has also been analyzed. An optimization algorithm has been applied to ex-post simulate the optimal management of the available flexible demand, production, and storage capacities in order to maximize the revenue/cost savings obtainable from the spot- and reserve electricity markets.

The results showed that in our case study, the grid exchange and peak load costs can be minimized through optimal management of the energy conversion and storage systems. Sensitivity analyses have been performed to investigate the role of the different thermal and electricity storage options. By valorizing the spot market, the thermal storage options' flexibility generates revenues reducing the yearly total expenses by about $28 \%$. Including the option of trading on the reserve market decreases the costs by an additional $16 \%$. As a consequence, this study definitely indicates the considerable value of the flexibility present in a building. However, harvesting this potential involves considering legal requirements, establishing decision rules for market bidding, prognosing market prices, as well as accurate estimations of local demand and supply. As we have shown the potential to be considerable but limited, we recommend future investigations to focus on cases which already now feature multi-energy systems that make use of their inherent flexibility.

The results showed that complementing the existing energy infrastructure with batteries would decrease the costs by about $43 \%$ if trading only on the spot market. When also including the option to trade on the reserve market, the costs decrease by an additional $20 \%$. In this last, most favorable scenario, the revenues created by the batteries would amortize their current market price in about 10 years, whilst not showing indications of an increased battery degradation rate. As a consequence, the maximum revenue that can possibly be generated by letting a battery storage system operate on both the spot and reserve markets only allows for payback of the acquisition and installation costs of the battery. Considering the lower revenues generated with a rolling horizon approach, additional costs due to maintenance, and the costs for capital, the economic viability is currently questionable. However, falling battery prices and government incentives might make such an investment economically profitable. In addition to other arguments, such as a contribution to the energy turnaround, this, as of today, convinces certain customers.

Author Contributions: Conceptualization, E.F.; Methodology, E.F. and B.R.; Software, G.v.d.W.; Validation, E.F., B.R. and A.B.; Formal Analysis, E.F. and B.R.; Investigation, E.F. and B.R.; Resources, E.F.; Data Curation, A.B.; Writing-Original Draft, Preparation, E.F. and B.R.; Writing-Review \& Editing, B.R.; Visualization, E.F. and B.R.; Supervision, E.F.; Project Administration, E.F. Funding Acquisition, E.F.

Funding: This research was funded by Innosuisse, this Swiss Innovation Agency.

Acknowledgments: This work has been accomplished in the frame of the Swiss Competence Center for Energy Research on Future Energy Efficient Buildings \& Districts SCCER FEEB\&D.

Conflicts of Interest: The authors declare no conflict of interest.

\section{References}

1. European Commission. European Commission Energy Roadmap 2050. Available online: https:/ / ec.europa. eu/energy/sites/ener/files/documents/2012_energy_roadmap_2050_en_0.pdf (accessed on 7 December 2018).

2. Geidl, M.; Koeppel, G.; Favre-perrod, P.; Klöckl, B.; Andersson, G.; Fröhlich, K. The Energy Hub-A Powerful Concept for Future Energy Systems. Networks 2007, 13-14. [CrossRef] 
3. Mancarella, P. MES (multi-energy systems): An overview of concepts and evaluation models. Energy 2014, 65, 1-17. [CrossRef]

4. Orehounig, K.; Evins, R.; Dorer, V. Integration of decentralized energy systems in neighbourhoods using the energy hub approach. Appl. Energy 2015, 154, 277-289. [CrossRef]

5. Orehounig, K.; Mavromatidis, G.; Evins, R.; Dorer, V.; Carmeliet, J. Towards an energy sustainable community: An energy system analysis for a village in Switzerland. Energy Build. 2014, 84, 277-286. [CrossRef]

6. Chicco, G.; Mancarella, P. Distributed multi-generation: A comprehensive view. Renew. Sustain. Energy Rev. 2009, 13, 535-551. [CrossRef]

7. Koirala, B.P.; Ávila, J.P.C.; Gómez, T.; Hakvoort, R.A.; Herder, P.M. Local alternative for energy supply: Performance assessment of integrated community energy systems. Energies 2016, 9, 981. [CrossRef]

8. Capuder, T.; Mancarella, P. Techno-economic and environmental modelling and optimization of flexible distributed multi-generation options. Energy 2014, 71, 516-533. [CrossRef]

9. Allan, G.; Eromenko, I.; Gilmartin, M.; Kockar, I.; McGregor, P. The economics of distributed energy generation: A literature review. Renew. Sustain. Energy Rev. 2015, 42, 543-556. [CrossRef]

10. Facchinetti, E. Eleven Business Opportunities emerging from the Energy Transition. Netw. Ind. Q. 2018, 20, 21-27.

11. Mancarella, P.; Chicco, G. Integrated energy and ancillary services provision in multi-energy systems. In Proceedings of the 2013 IREP Symposium Bulk Power System Dynamics and Control-IX Optimization, Security and Control of the Emerging Power Grid, Crete, Greece, 25-30 August 2013; pp. 1-19.

12. Ottesen, S.Ø.; Tomasgard, A.; Fleten, S.E. Prosumer bidding and scheduling in electricity markets. Energy 2016, 94, 828-843. [CrossRef]

13. Stadler, P.; Ashouri, A.; Marechal, F. Distributed model predictive control of energy systems in microgrids. In Proceedings of the 2016 Annual IEEE Systems Conference (SysCon), Orlando, FL, USA, 18-21 April 2016; pp. 1-6.

14. Jin, M.; Feng, W.; Liu, P.; Marnay, C.; Spanos, C. MOD-DR: Microgrid optimal dispatch with demand response. Appl. Energy 2017, 187, 758-776. [CrossRef]

15. Gonzalez, J.; Moriarty, J. Risk-sensitive optimal switching and applications to district energy systems. In Proceedings of the 2014 International Conference on Probabilistic Methods Applied to Power Systems (PMAPS), Durham, UK, 7-10 July 2014; pp. 1-6.

16. Haque, A.N.M.M.; Nguyen, P.H.; Bliek, F.W.; Slootweg, J.G. Demand response for real-time congestion management incorporating dynamic thermal overloading cost. Sustain. Energy, Grids Netw. 2017, 10, 65-74. [CrossRef]

17. Eid, C.; Grosveld, J.; Hakvoort, R. Assessing the costs of electric flexibility from distributed energy resources: A case from The Netherlands. Sustain. Energy Technol. Assess. 2019, 31, 1-8. [CrossRef]

18. Eid, C.; Codani, P.; Perez, Y.; Reneses, J.; Hakvoort, R. Managing electric flexibility from Distributed Energy Resources: A review of incentives for market design. Renew. Sustain. Energy Rev. 2016, 64, 237-247. [CrossRef]

19. Ottesen, S.Ø.; Tomasgard, A.; Fleten, S.E. Multi market bidding strategies for demand side flexibility aggregators in electricity markets. Energy 2018, 149, 120-134. [CrossRef]

20. Ralon, P.; Taylor, M.; Ilas, A.; Diaz-Bone, H.; Kairies, K.-P. Electricity Storage and Renewables: Costs and Markets to 2030; International Renewable Energy Agency: Abu Dhabi, United Arab Emirates, 2017.

21. Baumann, T.; Baumgartner, F. Home Batteriespeicher-Studie für Solarspar; ZHAW SoE: Winterthur, Switzerland, 2017.

22. Astaneh, M.; Dufo-López, R.; Roshandel, R.; Bernal-Agustin, J.L. A novel lifetime prediction method for lithium-ion batteries in the case of stand-alone renewable energy systems. Int. J. Electr. Power Energy Syst. 2018, 103, 115-126. [CrossRef]

23. Raszmann, E.; Baker, K.; Shi, Y.; Christensen, D. Modeling stationary lithium-ion batteries for optimization and predictive control. In Proceedings of the 2017 IEEE Power and Energy Conference at Illinois, Champaign, IL, USA, 23-24 February 2017.

24. Wu, R.L.K. Reliability Optimisation of District Multi-Energy Systems; Swiss Federal Institute of Technology Zurich: Zurich, Switzerland, 2016. 
25. Prasanna, A.; Dorer, V.; Vetterli, N. Optimisation of a district energy system with a low temperature network. Energy 2017, 137, 632-648. [CrossRef]

26. Waibel, C.; Mavromatidis, G.; Bollinger, A.; Evins, R.; Carmeliet, J. Sensitivity analysis on optimal placement of façade based photovoltaics. In Proceedings of the ECOS 2018-The 31st International Conference on Efficiency, Cost, Optimization, Simulation and Environmental Impact of Energy Systems, Guimarães, Portugal, 17-22 June 2018.

27. Schweizerische Gesamtenergiestatistik 2017. Bern, Germany, 2018. Available online: http://www.bfe. admin.ch/php/modules / publikationen/stream.php?extlang=de\&name=de_936120762.pdf (accessed on 14 December 2018).

28. Misurio Optimizer. Available online: https://www.misurio.ch/misurio-optimizer_en.html (accessed on 3 October 2018).

29. TrinaCommercial 18 Power: Product Description. Available online: http:/ /www.trinaenergystorage.com/ uploads/download/152721701760.pdf (accessed on 3 October 2018).

(C) 2018 by the authors. Licensee MDPI, Basel, Switzerland. This article is an open access article distributed under the terms and conditions of the Creative Commons Attribution (CC BY) license (http:// creativecommons.org/licenses/by/4.0/). 